\title{
O BRASIL E OS CHAMADOS BLOCOS REGIONAIS
}

José Augusto Guilhon Albugueroue

Resumo: A hipótese de formação de blocos regionais rivais não se realizou. O Brasil tem hoje a possibilidade de aprofundar sua inserção de modo complementar em dois arranjos regionais - a Alca e o Mercosul - e um arranjo inter-regional, entre o Mercosul e a União Européia. A negociação da Alca é a mais importante das três porque estabelece a referência a partir da qual o Brasil definirá seu papel no mundo.

Palavras-chave: blocos regionais de comércio; Alca; Mercosul.

Abstract: Contrary to expectations, the formation of competing trade blocks has not become a reality. Today, Brazil has the opportunity to play a larger role in two regional associations - the FTAA and Mercosul - as well as in the inter-regional arrangement between Mercosul and the European Union. FTAA membership is the most important of the three, providing as it would a point of reference from which Brazil can define its role in the world.

Key words: regional trading blocks; FTAA; Mercosul.

A

noção de blocos comerciais foi moeda corrente no início da década de 90 , forjada a partir da expectativa de que, com o fim da polarização política e militar, os interesses econômicos iriam predominar nas relações internacionais. Como decorrência dessa predominância, os conflitos internacionais tenderiam a opor interesses comerciais que redundariam, por sua vez, na formação de blocos, a exemplo dos blocos americano e soviético durante a Guerra Fria.

Por essa ótica, as guerras comerciais substituiriam as guerras propriamente ditas, e se poderia esperar um aumento da interdependência comercial intrablocos e um aumento do protecionismo interblocos. Dada a disputa pela liderança na competitividade internacional, que deixou os Estados Unidos atrás de seus parceiros europeus e japoneses até o início do governo Clinton, em 1993, previa-se que os principais candidatos a liderar um bloco seriam precisamente a Alemanha e o Japão.

A forte implantação regional de suas respectivas economias, a da Alemanha na CEE e a do Japão estendendo-se em círculos concêntricos entre os "tigres" e, posteriormente, no Sudeste Asiático, levava a crer que os blocos que daí resultariam teriam caráter regional. E o exemplo bem-su- cedido da CEE permitia prever que ela forneceria o modelo de integração, baseado na forte liberalização interna com considerável margem de protecionismo externo: a fortaleza econômica. Deve-se lembrar que, após um período de euroceticismo, a CEE estava a caminho do Mercado Único em 1993 e já preparando a negociação do futuro Tratado de Maastricht, que resultou na União Européia, com unificação da moeda e da política externa e de defesa.

Aos Estados Unidos, em parte devido a sua perda de competitividade, em parte devido às barreiras comerciais de seus principais parceiros, restaria o caminho da regionalização, já então iniciado com o Acordo de Livre Comércio celebrado com o Canadá. Esse acordo teve continuidade com as negociações, iniciadas em 1991, com o México e, posteriormente, com o Canadá, para a adoção do Nafta. A proposta de adoção de uma área de livre-comércio continental, embutida na Iniciativa para as Américas do presidente Bush senior, era tida por alguns como consolidação de um bloco sob hegemonia regional americana e, por outros, como manobra diversionista, mas nunca como contra-argumento.

Naquele momento, em que não se conhecia a extensão da débâcle política e militar da ex-União Soviética, ainda era 
possível prever a constituição de um quarto bloco, formado a partir da Comunidade dos Estados Independentes, sob a liderança da Federação Russa. Era uma hipótese a ser formulada. Quanto ao Mercosul, ainda em processo de formação, previa-se um isolamento que o condenaria à irrelevância diante da dimensão dos demais blocos, ou um destino de inexorável absorção num futuro bloco americano.

A proposta, então avançada pelos Estados Unidos, de criação de uma área de livre-comércio inter-regional, unindo as duas orlas do pacífico a partir da Apec, ${ }^{1}$ não cabia, obviamente, no modelo de blocos regionais. Mas, em vez de ser utilizada para infirmar a hipótese era, ao contrário, empregada como prova contrafactual. Ela constituiria, tal como a Iniciativa Bush, uma alternativa para o objetivo realmente buscado pelos Estados Unidos: a formação de uma fortaleza comercial regional, restrita à América Setentrional.

Passada uma década, apenas a UE evoluiu de maneira fiel ao próprio modelo de bloco ao mesmo tempo comercial, financeiro, regulatório, político e de segurança, embora não tenha enveredado, como se temia, por um fechamento comercial crescente. Tampouco se expandiu na velocidade prenunciada com o fim da Guerra Fria, em direção a uma incorporação rápida e total da Europa ex-soviética, do Oriente Próximo e das antigas colônias.

A incorporação dos países circunvizinhos está na agenda, assim como a unificação da política externa e de defesa, mas apenas a unificação monetária está prestes a efetivar-se por completo. O protecionismo sofreu derrotas formais - como o compromisso de aprofundar a liberalização da agricultura e de indústrias e serviços sensíveis e obteve vitórias de fato - como a reintrodução de novos argumentos a favor dos subsídios. Mas a UE não é hoje significativamente mais protecionista do que a CEE antes de Maastricht. Longe de isolar-se, a UE se mantém em movimento na direção de acordos comerciais com a Ásia do Leste, a África Austral e a América do Sul.

Com relação ao Japão, não parece ter havido um movimento significativo em direção à criação de um bloco tal como previsto. Em sua região convivem várias iniciativas regionais (como a Asean ${ }^{2}$ ) e inter-regionais (como a Apec e a Falal ${ }^{3}$ ), nenhuma organizada em torno de um acordo comercial. O movimento mais relevante do Japão, até o final do ano 2000, consistiu, ao contrário, em não apoiar qualquer processo rápido de criação de blocos de natureza regional ou inter-regional em sua área de influência.

Pode-se notar, em função do apoio dado ao Falal (Kojima, 2001) e do interesse demonstrado pelas autoridades comer- ciais japonesas pelas experiências de integração econômica regional, como o Mercosul e a Alca, que o Japão começa a rever sua política de não se engajar formalmente em acordos regionais de comércio. Atualmente, encontram-se em negociação acordos de comércio com dois "tigres" asiáticos, Singapura e Coréia do Sul, e com o que há de mais próximo de "tigres" latino-americanos, México e Chile.

Com relação aos Estados Unidos, as iniciativas tomadas no que diz respeito a acordos comerciais definitivamente não confirmam a exclusividade, sequer a prioridade concedida à formação de uma fortaleza regional. A literatura aponta, ao contrário, a tentativa de abrir novas opções na direção da liberalização dos mercados para as exportações e os investimentos americanos.

Com o impasse criado nas negociações da Rodada Uruguai do GATT, os EUA procuraram negociar acordos que incluíssem os temas em que eram demandeurs no GATT, tais como liberalização de serviços e regulação de propriedade intelectual e investimentos. A iniciativa de um acordo de livre-comércio com o México, proposto por este, foi direcionada para esse objetivo. Simultaneamente, os EUA tomaram iniciativas semelhantes com relação à América Latina e à Ásia-Pacífico.

Tais iniciativas tinham dois objetivos: aumentar a pressão em favor de um desenlace favorável no GATT e, caso a Rodada Uruguai fracassasse definitivamente, dispor de alternativas para exportações e investimentos americanos dentro das condições que lhes pareciam mais favoráveis. Com o resultado relativamente satisfatório da Rodada Uruguai, tais iniciativas deixaram de ser prioritárias, arrefecendo o interesse inicial.

Entretanto, a estagnação das negociações para a criação de áreas de livre-comércio na Ásia-Pacífico e nas Américas não pode ser explicada por um movimento de isolamento regional dos EUA. Longe disso. O sucesso relativo da Rodada Uruguai colocou em segundo plano essas iniciativas justamente porque corresponde a uma prioridade global acima de uma prioridade regional. A estagnação das tratativas para a constituição de uma área continental de livre-comércio deveu-se à falta de apoio do Brasil e à oposição de grupos de interesse domésticos nos Estados Unidos. E, no caso da Apec, o empecilho veio da oposição de países da Asean e à falta de apoio do Japão. Em nenhum dos três casos se pode falar na predominância de um movimento isolacionista regional americano.

Fora dessa esperada divisão do mundo em blocos liderados pelos três grandes, ocorreu uma grande difusão de acordos comerciais nas mais diversas regiões, ou unindo 
diferentes regiões. No primeiro caso, dificilmente se poderia falar em fortalezas comerciais ou blocos tendendo a um isolacionismo e preparados para guerras comerciais.

Faltariam, na maioria dos casos, recursos econômicos e de poder para qualquer pretensão de disputa hegemônica com outros blocos. Isso se aplica, por exemplo, aos arranjos comerciais da América Central e do Caribe, da África Austral, da Ásia Central.

Quanto aos arranjos inter-regionais, como os celebrados entre a UE e o México e os que estão sendo negociados entre a UE e o Chile, ou entre o Japão e cada um desses países, eles atestam, ao contrário, o grau de flexibilidade dos arranjos existentes. O México, membro do Nafta, nem por isso se vê privado de estabelecer inúmeros acordos, tanto no continente como fora dele.

Assim sendo, a questão dos blocos regionais tem de ser recolocada, hoje, de maneira diferente daquela como era encarada na virada da década passada. Para o Brasil ela não se coloca em termos excludentes, mas sim em termos de um leque de opções complementares. Quais são essas opções?

Para responder a essa questão pode-se partir dos fatos ou das idéias. Isto é, partir dos acordos existentes ou em vias de negociação, ou partir dos objetivos e interesses em jogo. O segundo método é o que convém a um estudo policy-oriented. $\mathrm{O}$ primeiro é mais apropriado a uma abordagem acadêmica. Neste artigo serão combinados, na medida do possível, esses dois métodos.

\section{A TRÍADE ESTRATÉGICO-COMERCIAL}

A economista Vera Thorstensen tem empregado a expressão Tríplice Aliança para evocar o linkage existente entre as principais frentes de negociação internacional em que o Brasil se encontra envolvido, a nova rodada global no âmbito da $\mathrm{OMC}$, as negociações da Alca e as negociações entre o Mercosul e a UE. No que se refere a blocos regionais ou, mais propriamente, a arranjos regionais de comércio, as opções do Brasil concentram-se principalmente em três frentes, que em grande parte recobrem as negociações apontadas por ela. Trata-se da integração subregional no Mercosul, da integração continental na Alca e da integração inter-regional com a UE.

Essa tríade de processos interligados de integração, além do aspecto comercial, envolve outro, estratégico, porque a opção excludente de um desses arranjos em detrimento dos demais, ou a exclusão de um deles em favor dos demais deveria pressupor uma escolha do "nosso can- to" no mundo globalizado. Isso porque tal opção implicaria uma escolha a respeito do núcleo de economias nacionais, mais ou menos integradas transnacionalmente, dentro e a partir do qual se processa a integração brasileira na economia global. E, por decorrência, nas relações internacionais de poder.

Em outras palavras, pode-se chamar essa tríade de estratégico-comercial porque a prioridade política concedida a uma delas deveria envolver uma parte substancial de nossa identidade externa. O objetivo é apresentar o Brasil como uma economia emergente - do bloco do eu-sozinho - como a economia líder do Mercosul, como a segunda economia do continente americano, ou como a economia líder de um dos arranjos laterais da economia da Europa Ocidental?

É uma referência à prioridade política de longo prazo, $\mathrm{e}$ não à urgência pragmática de curto prazo. A diferença entre as duas é que, no primeiro caso, não importa se o objetivo é atingido em primeiro ou em último lugar, o que importa é que todos os demais objetivos lhe sejam subordinados e possam ser sacrificados em seu benefício. No segundo, entretanto, trata-se de um objetivo que pode até vir em primeiro lugar, por estar ao alcance a um custo mais baixo, mas que poderá, a qualquer momento, ser prejudicado em benefício de outro. $\mathrm{O}$ argumento é que, a menos que se aceite o pressuposto de que a agenda de nossa política externa pode ser totalmente definida do exterior, a prioridade excludente de uma dessas opções de integração deveria basear-se na consideração prévia de uma hierarquia de objetivos e de prioridades políticas e econômicas.

O caso do Mercosul é ao mesmo tempo o mais complexo e o mais simples. Mais complexo porque o Mercosul é o marco fundador das relações internacionais brasileiras. Ainda como parte integrante do Império luso, a Bacia do Prata constituiu o primeiro teatro de cooperação e conflito com outra potência soberana, ${ }^{4}$ processo que se intensificou a partir do final do século, com a fusão das duas coroas ibéricas.

Nossas fronteiras na Bacia do Prata foram desde sempre vivas e densas tanto do ponto de vista econômico, quanto cultural, político ou militar. O mesmo não ocorreu com o resto do território brasileiro, onde as fronteiras naturais separavam em vez de integrar e, a tal ponto, que era como se não houvesse vizinhos. Não fosse nossa relação internacional com os "castelhanos" e com seus herdeiros, teríamos permanecido até o século passado no esplêndido berço do isolamento em nosso próprio território continental. 
Isso faz com que se possa considerar a Bacia do Prata - não propriamente o Mercosul - um destino, na expressão de Celso Lafer, mais do que uma opção. Não que não tivesse sido possível, desde o início de nossa vida independente, subordinar nosso "destino" platino a nossas opções transatlânticas. Não a principal alternativa do Brasil, na virada do século XIX para o século XX, não fosse entre prosseguir atrelado ao evanescente império britânico ou se integrar ao nascente império americano, enquanto a Argentina permanecia fiel aos seus laços europeus. Um destino assim entendido pode permanecer latente durante séculos antes de ser assumido, como ocorreu com a fase de cooperação e integração com a Argentina iniciada nas décadas finais do século XX.

$\mathrm{O}$ aspecto da complexidade do Mercosul está em que as diversas dimensões do "destino" platino do Brasil estão profundamente interligadas nas Actas de Iguazú ${ }^{5}$ e no Tratado de Assunção ${ }^{6}$ que as sucedeu. Assim sendo, algo como um "Mercosul", em que poderá eventualmente sobressair-se uma ou outra das dimensões do comércio, da segurança, da cultura, dos direitos e valores globais em detrimento das demais, deveria, ao menos potencialmente, fazer parte de nosso "destino".

Tendo em vista a complexidade da interdependência brasileira com os vizinhos do Cone Sul e, especialmente, com a Argentina, a tarefa de determinar qual a natureza prioritária do Mercosul, entre tantas, é extremamente difícil. Por outro lado, a única resposta possível é sim, o Mercosul tem de existir.

Não obstante, o caso do Mercosul é o mais simples devido à crise, no momento insolúvel, em que se encontra. Como a crise é, atualmente, insolúvel, não há alternativas: a saída é aquela atribuída a Getúlio Vargas - deixar como está para ver como fica.

$\mathrm{Na}$ verdade, a crise do Mercosul é a conjunção de três crises: aquela decorrente da desvalorização do real, que afetou negativamente o conjunto das economias do bloco; a crise decorrente da crise argentina, que levou esse País a um grau de volatilidade fiscal e comercial que, na prática, revogou a união aduaneira existente entre os quatro países; e, finalmente, a crise desencadeada com a alteração da posição brasileira em relação à Alca.

Dentro de sua múltipla funcionalidade, o formato do Mercosul, como área de livre-comércio e união aduaneira, estabeleceu uma solução oposta e complementar aos objetivos da política econômica externa do Brasil e da Argentina. Para o Brasil, o Mercosul tem sido o principal instrumento para limitar o aumento de sua interdependên- cia econômica com os Estados Unidos, sem isolar-se da economia da região. Para a Argentina, o Mercosul tem sido o principal instrumento para elevar suas chances de aumentar os ganhos de uma maior interdependência econômica com os Estados Unidos, na medida em que incluiria o Brasil como fator equilibrador dessa interdependência.

Assim sendo, o Brasil não quer que a Argentina se integre na economia americana porque não deseja se integrar, enquanto a Argentina não quer se integrar na economia americana enquanto o Brasil não se integrar, se possível pela mão da própria Argentina. A Argentina, por sua vez, não deseja que o Brasil se integre na economia americana sem levá-la junto, enquanto o Brasil deseja conter ou, pelo menos, retardar essa integração. Portanto, embora os objetivos sejam opostos, os dois países têm coincidido num ponto: Brasil e Argentina devem retardar, a curto prazo, o aumento da integração de ambos na economia americana.

Uma hipótese é que o fator mais agravante da crise do Mercosul consiste na mudança de posição do Brasil com relação à Alca, tornando o Mercosul irrelevante para o principal objetivo comum de seus dois protagonistas. A partir do momento em que o Brasil reconheceu a inevitabilidade da Alca e decidiu negociar a limitação de seus supostos inconvenientes e a ampliação dos eventuais benefícios daí decorrentes, o principal objetivo comum do Brasil e da Argentina no Mercosul - retardar a adesão de ambos à Alca - tornou-se secundário.

Se isso é verdade, o Mercosul deixa de ser um objetivo em si mesmo, e seu caráter instrumental passa a prevalecer. Duas perspectivas abertas recentemente passam, possivelmente, a justificar o emprego do Mercosul pelo Brasil no processo de construção de seu espaço econômico internacional. Trata-se, por um lado, do novo impulso ganho pelas negociações inter-regionais entre Mercosul e UE, após a oferta tarifária feita pela UE na reunião de julho de 2001 da CNB. ${ }^{7}$ Como o formato das negociações é bilateral UE/Mercosul, e o mandado da UE é para negociações com o Mercosul, e não com seus países-partes individualmente, o Mercosul, independentemente da resolução de sua crise interna, tornou-se o fórum para a elaboração da agenda e o canal para a negociação comercial com os parceiros europeus.

O Mercosul teria até outubro de 2001 para apresentar uma contraproposta à oferta européia e, até lá, essa seria sua tarefa prioritária, passando à frente das negociações da agenda interna do Mercosul. Não o será necessariamente, porque o governo dos EUA, por ocasião do anúncio do novo empréstimo do FMI à Argentina (Folha de S.Paulo, 
22/08/01), propôs o início de conversações bilaterais com o Mercosul com vistas à adoção de um acordo de comércio.

Essa nova frente de negociação obedeceria ao formato $4+1$ do acordo-quadro firmado entre os EUA e os quatro países do Mercosul no âmbito da Iniciativa das Américas, o chamado Acordo do Jardim das Rosas (Albuquerque, 2001). Com a derrota de George Bush nas eleições presidenciais de 1992 e o lançamento da Alca em 1994, aquele acordo perdeu sua relevância, mas foi repescado recentemente na reunião de Assunção do Conselho do Mercosul em junho de 2001, por iniciativa do Uruguai, que propôs a abertura de negociações do Mercosul com os EUA em paralelo às negociações da Alca.

Assim sendo, em que pese sua crise interna, o Mercosul retoma uma relevância de primeiro plano por se tornar um instrumento essencial de negociação comercial externa do Brasil com seus principais parceiros, os EUA e a UE. Isso em princípio lhe garante, de antemão, uma sobrevida até 2005, prazo para o final das negociações da Alca ou, se for o caso, até o final das negociações da anunciada Rodada do Milênio da OMC. Ao mesmo tempo, seu caráter instrumental descarta o Mercosul como prioridade política de integração econômica.

A UE constitui o outro caso. Do ponto de vista das negociações comerciais e paracomerciais (isto é, de trade and trade-related issues), a integração econômica interregional com a UE é um processo tão ou mais complexo quanto o da Alca. Do ponto de vista da multiplicidade de atores, são quinze países de um lado e quatro do outro, teoricamente cada lado falando em uníssono mas, de fato, uma negociação pelo menos em dois níveis (se for excluído o nível doméstico de cada país dos dois blocos).

São negociações comportando um grande grau de desequilíbrio, não apenas entre as economias das duas regiões, mas também entre os países de cada bloco. Não existe, porém, como existe na Alca, um protagonista claramente delimitado, no caso os EUA (e de certa forma, do outro lado, seu principal interlocutor na Alca, o Brasil). Falta à UE uma liderança unilateral com relação à política comercial, o que permite certa deriva entre interesses e estratégias repartidos entre a França, a Alemanha, a Inglaterra - apenas para mencionar os três grandes.

Finalmente, do ponto de vista da simetria das negociações, a UE, tal como os EUA, pretende o máximo de abertura de seus parceiros de ultramar, enquanto quer manter reservada como inegociável uma área significativa de comércio, cuja dimensão é quase impossível estimar a priori. $\mathrm{O}$ que distingue o caso da UE do caso dos EUA com rela- ção aos interesses comerciais brasileiros, é que a área reservada por este último é mais delimitada e restrita e de estimativa mais factível, enquanto na UE esbarra-se em questões intricadíssimas de princípio e de política doméstica, como é o caso da política agrícola comum.

A limitação da prioridade política que se pode conceder à integração inter-regional é que ela é inter-regional. A "cartada européia" sempre foi, para o Brasil, um ponto de apoio para contrabalançar as enormes assimetrias com seu principal parceiro no Continente americano, os EUA. Desse ponto de vista, a integração UE/Mercosul vem servindo para o que foi concebida, isto é, evidenciar para os EUA que o Brasil tem alternativas.

Hoje é inegável que cada avanço ou retrocesso nas negociações da Alca provoca um sacolejo no tabuleiro inter-regional, e vice-versa. De fato, a UE reagiu com inusitada rapidez ao pedido do Mercosul para que formulasse uma proposta de liberalização comercial. Isso ocorreu depois de cinco anos em que se marcou passo sem que a UE autorizasse um mandato negociador com relação ao Mercosul, da assinatura do Acordo Quadro, em 1995, à Cimeira do Rio, em 2000. Pode-se creditar a atual aceleração do processo, num contexto em que a UE reiterava sempre que a integração era sobretudo política, aos avanços da Alca na Cúpula de Quebec. ${ }^{8}$

Por mais que se queira, entretanto, o Brasil dificilmente será uma potência européia, mesmo no sentido em que os EUA foram, durante toda a Guerra Fria, a maior potência européia e a maior potência asiática. E se, capaz de amealhar todos os recursos necessários para exercer, na Europa, algum papel relevante, o Brasil estivesse disposto a pagar o preço econômico, político e militar desse exercício, teria certamente mais vantagem em exercê-lo em seu continente.

\section{A OPÇÃO CONTINENTAL}

Esse conjunto de considerações converge no sentido de apontar para a própria região brasileira como sendo o foco principal de seus objetivos políticos. Isso não destoa do princípio quase universal de que nenhuma potência pode ter alcance mundial sem ter necessariamente uma forte implantação regional. Ou, em outros termos, não é possível uma potência deter relevância mundial sem pelo menos disputar a hegemonia regional.

Dito isso, o leque de opções brasileiras se reduz ao Cone Sul ou a todo o continente americano. Dentro dessa ordem de idéias, há dois fortes argumentos em apoio à se- 
gunda opção. O primeiro, de caráter factual, baseia-se na evidência do caráter instrumental do Mercosul, tanto para o Brasil como para a Argentina: enquanto o Mercosul se justificar exclusivamente pela oportunidade que confere a seus membros para negociar com terceiros - no caso a UE e os EUA -, ele não pode aspirar a ser o objetivo central da política externa do Brasil.

O segundo argumento é de caráter conceitual. O lugar de um país no mundo pode ser definido em termos locais, regionais ou globais. Exemplo do primeiro caso seria um país cuja principal aspiração no mundo é sobreviver a seus vizinhos. Israel e um hipotético futuro Estado palestino estão enredados nesse tipo de destino.

O segundo caso, regional, talvez possa ser aplicado à Rússia. Por mais que esse país tente recuperar um destino global, de longe comparável ao de que desfrutou na Guerra Fria, sua atuação internacional tende a ser mais relevante em torno do que fora a Grande Rússia.

O último caso corresponde a todas as grandes potências que, bem ou mal, mantiveram relevância sistêmica após o fim da Guerra Fria, como os EUA, a Inglaterra e a França, e também aquelas que almejam algum grau de relevância global no futuro. Todas detêm ou disputam a hegemonia regional, como foi assinalado há pouco.

Assim sendo, a menos que renuncie a ter sua identidade e sua agenda definidas de fora para dentro, e a menos que renuncie a ter um mínimo de relevância global e regional, o papel do Brasil no mundo não cabe no Mercosul. A identidade nacional de um país como o Brasil não pode ser definida em termos locais.

Isso direciona as opções do Brasil para o âmbito do continente americano, quer o principal objetivo seja ter relevância regional ou global. Dessa forma, seria pertinente definir seu principal objetivo externo na região, como sendo o de principal interlocutor dos EUA no continente, tanto do ponto de vista político como econômico e de segurança e defesa. Isso já lhe asseguraria, de per si, um papel de relevância global que, no entanto, não teria por que se limitar a um papel regional. Se o tão propalado futuro, a que o Brasil pertence, um dia chegar, essa base regional de relevância sistêmica será uma das condições indispensáveis para que este País se torne um dos protagonistas da ordem mundial.

Se isso for correto, a importância estratégico-comercial da Alca será medida por sua pertinência no alcance dos objetivos intrínsecos do Brasil, não em reação aos interesses dos EUA, ou dos demais países, no continente. Desse ponto de vista, as negociações da Alca seriam as mais im- portantes porque são as mais relevantes para a definição dos objetivos de liderança regional inerentes aos objetivos políticos globais do País. Tanto as negociações com a UE como a esperada Rodada da OMC lhe seriam subordinadas, porque delas depende a consolidação do papel de liderança continental do Brasil, perspectiva da qual se poderá avaliar o alcance dos ganhos e concessões a serem porventura acordados no âmbito desses dois foros.

Em contrapartida, isso implica uma reversão de expectativas em relação à Alca. Ela só passa a ser relevante, no que diz respeito aos objetivos maiores do País na medida em que seja relevante para consolidar seu papel de liderança regional. Desse modo, o objetivo tático de retardar ou minimizar perdas comerciais é menos relevante do que um protagonismo eficaz. Por protagonismo eficaz entenda-se o exercício efetivo da liderança e da interlocução entre atores com relevância sistêmica. Isto é, o fato de um ator fazer parte do núcleo de atores que controla de fato o sistema decisório. No caso da Alca, o número não superior a quatro ou cinco países que decidirão o futuro desse acordo.

Se assim for, a co-presidência do Brasil e dos Estados Unidos no processo negociador da Alca é infinitamente mais relevante para os objetivos brasileiros no continente do que toda a década de protelação do processo negociador, motivado pelo objetivo de diminuir eventuais perdas comerciais com a adoção e entrada em vigor do acordo. Mais relevante, inclusive, do que a vitória da diplomacia brasileira na sua resistência contra a antecipação de sua data de vigência.

Como observado anteriormente, "nenhum país anfitrião se sente à vontade com o fracasso de uma reunião da qual ele é sede. Se existe um inconsciente dos Estados-Nação ${ }^{9}$ - e deve-se admitir que Freud disse explicitamente que não -, quando a diplomacia brasileira aceitou hospedar o Fórum (Empresarial) e a Reunião Ministerial de Belo Horizonte e, depois de Santiago, admitiu co-presidir a fase final de negociação da Alca, inconscientemente o destino estava selado" (Albuquerque, 2001). Se isso é verdade, o inconsciente estratégico do Brasil - que o defende, com "atos falhos", dos objetivos inconsistentes de sua política externa - falou mais alto.

\section{CONCLUSÕES}

Tudo o que foi dito autoriza a formulação de algumas conclusões sobre as prioridades brasileiras com relação aos chamados blocos comerciais. Em primeiro lugar, é necessário estabelecer uma hierarquia de precedência entre 
os três blocos em cujas negociações o Brasil está engajado. Tal hierarquia não pode ser reduzida exclusivamente à importância do fluxo de comércio. Além das dimensões de endividamento externo e investimento direto, que não se confundem com o fluxo de comércio, embora este possa se tornar um fator positivo na sustentabilidade daqueles, é necessário considerar os objetivos políticos do País.

Assim, os argumentos acima convergem na direção de outorgar à Alca o primeiro lugar na hierarquia dos blocos com interesse para o Brasil, porque ela é mais condizente com os interesses globais de nosso país ser identificado como a segunda maior potência do continente, e não apenas como a maior potência do Mercosul. Vem em seguida o Mercosul, com as convenientes revisões de rumo, na direção apontada, por exemplo, em "Integração regional na América do Sul e a agenda multilateral pós-Seattle" (Motta Veiga, 2000).

As negociações com a UE, entretanto, com a grande importância instrumental que de fato possui, viriam apenas em terceiro lugar e deveriam ser subordinadas aos eventuais resultados de uma futura rodada global de negociações na OMC - precisamente porque é assim que querem os europeus, assim como corresponde tudo o que é relevante para os interesses comerciais do Brasil.

\section{NOTAS}

1. Asia Pacific Economic Cooperation.
2. Association of South East Asian Nations.

3. Forum América Latina-Ásia do Leste.

4. Como as populações indígenas não formavam estados nacionais, não se está considerando suas relações com os conquistadores como internacionais em sentido estrito.

5. Protocolo assinado pelos presidentes Alfonsín e Sarney prevendo a criação de uma Área de Livre Comércio entre os dois países.

6. Tratado firmado entre Argentina, Brasil, Paraguai e Uruguai criando o Mercosul.

7. Comissão de Negociação Birregional, fórum das negociações entre os dois blocos.

8. Raciocínio análogo cabe com relação à rapidez com que os EUA responderam à proposta uruguaia de negociação bilateral com o Mercosul, sobre a qual, tudo indica, o governo brasileiro ainda não tem posição firmada.

9. Ou das coletividades e instituições, para ser mais preciso.

\section{REFERÊNCIAS BIBLIOGRÁFICAS}

ALBUQUERQUE, J.A.G. "A Alca na política externa brasileira”. Política Externa. São Paulo, ago.-out. 2001.

KOJIMA, T. "Future Perspective of Fealac". Carta Internacional.98, abr. 2001.

MOTTA VEIGA, P. da (org.). O Brasil e os desafios da globalização. Rio de Janeiro, Relume Dumará/Sobeet, 2000.

José Augusto Guilhon Albuquerque: Professor de Relações Internacionais do Departamento de Economia da FEA-USP e Coordenador Científico do Núcleo de Pesquisa em Relações Internacionais da USP. 